\title{
面心立方 $\mathrm{Ni}-\mathrm{Co}$ 合金結晶の磁区模様*
}

\section{山本 美喜雄** 谷口哲 ${ }^{* *}$}

Mikio Yamamoto and Satoshi Taniguchi: Ferromagnetic Domain Patterns on Face-Centered Cubic Nickel-Cobalt Alloy Crystals (Ferromagnetic Domain Patterns on Ni-Co Alloy and Pure Cobalt Crystals, I). Ferromagnetic domain patterns have been observed, using the powder pattern technique, with single crystals of Ni-Co alloys containing $4,6,12,18,20$, and $68 \%$ Co. Annealed $4 \sim 20 \% \mathrm{Co}-\mathrm{Ni}$ single crystais revealed maze patterns after fairly severe electrolytic polish and proper domain patterns only after quitely severe electrolytic polish. Analysis of the observed domain patterns indicates that the first magnetocrystalline anisotropy constant, $K_{1}$, is positive for $4 \sim 18 \% \mathrm{Co}$, while it is negative for $20 \% \mathrm{Co}$. A domain pattern observed on a locally strained (100) surface of a $12 \% \mathrm{Co}-\mathrm{Ni}$ single crystal, which consists of $180^{\circ}$ domain walls radiating from the loaded point, shows that the internal stress in the surface layer takes a distribution concentric around the loaded point. $68 \% \mathrm{Co}-\mathrm{Ni}$ single crystals revealed domain patterns characteristic to face-centered cubic crystals with $K_{1}<0$.

(Received December 2, 1960)

\section{I. 緒霉}

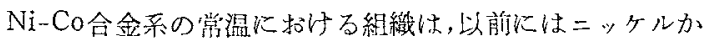

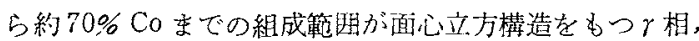
それからコバルトをでは稠密六方構造をもつ ク，そしてその中聞に約 $2 \%$ Co の狭小な 2 相籍囲がある とされていたが(1)，その後著者之協力者がこの合金系の密

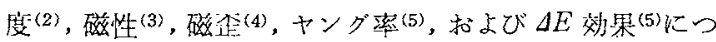
いて行つた研究の結果から， $\gamma+\varepsilon$ 相範用は約 $68 \sim 78 \% \mathrm{Co}$

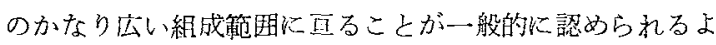

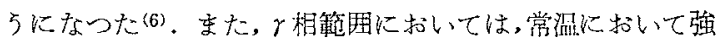

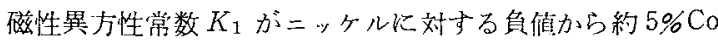
の添加比よつて正值に恣わるが，乙かし約 $19 \%$ を超える と再び負僆に戻り，そしてこの $K_{1}$ の符号の変化之共に容 易磁化方向が $\langle 111\rangle \rightarrow\langle 100\rangle \rightarrow\langle 111\rangle$ 之変ることが既性の测 定から知られている(3)(7)。一方，を相範囲については，コ パルトの容易磁化方向は常温においては〈0001〉方向であ

***東北大学金属材料研炎所

* 1960 年 10 月日本金属学会第 7 (電磁领材料)分科比 括いて講演； $\mathrm{Ni}-\mathrm{Co}$ 合金および純 $\mathrm{Co}$ 結晶の磁区模 椂， I.

(1) M.Hansen: Der Aufbau der Zweistofflegierungen, (1936), 498 .

(2) 山本: 本誌, 11 (1947) No.11-12; Sci. Rep. RITU, A2 (1950), 871.

(3) 11本: 本诂, $11(1947)$, No.11-12; 13(1949), No.6; Sci. Rep. RITU, A4 (1952), 14. I1本, 谷口, 星: 本誌, 17(1953),615; Sci. Rep. RITU, A6(1954), 539 .

（4）山本和よび宫沢：本誌，B15(1951)，505; Sci. Rep. RTTU, A5 (1953), 22.

(5) 山本：本誌 12(1948), No.2-3; 山本および谷口: 本 誌, B15 (1951) ,337,Sei. Rep. RITU,A6 (1954), 35.

(6) M.Hansen: Constitution of Binary Alloys, (1958), 485.

(7) J.W.Shih: Phys. Rev., 50(1936),376. L.W, Mckeehan: Phys. Rev., 51 (1937), 136.
るが、コバルトに二ッケル类添加しても容易磁化方向が変 らないか甭かはイイ期である。

ところで，Ni-Co 合金結晶の磁区嵀造については，純二

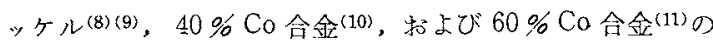

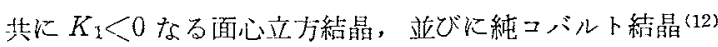
の磁区模様が粉模樣技衔によつて観察されているだけであ つて， $K_{1}>0$ なる組成䉇团扰よび 2 相範用の Ni-Co 合金 結晶の磁区模倳は研究されたことがないなお゙，Bates 特 よび Issac(13)性21，29，46，卢よび59\% Co-Ni 合金の多結 晶陚料について磁区模椂を研究したが，21\% Co-Ni 合金

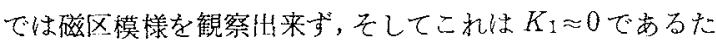
めであるといつている。

そこで，著者は Ni-Co 合金について $K_{1}>0$ なる組成範 用をたしかめると斯に $K_{1} \approx 0 な る$ 金属結晶の磁区構造に ついて知機をえ，また $\gamma$ 相範国の境界をたしかめるととあ

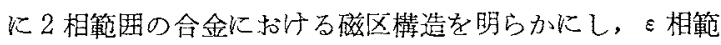

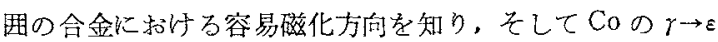

(8) 山本和よび岩田: Phys. Rev., 81(1951),887; Sci. Rep. RITU,A5 (1953) ,443; A8 (1956),293.

(9) H.J.Williams and J.G.Walker: Phys. Rev., 83 (1951),634. L.F. Bates and G.W.Wilson: Proc. Phys. Soc., A64 (1951),691; A66 (1953), 819. W.Stephan: Exp. Tech. Physik., 3 (1955), 1. U. Martius, K.V. Gow and B. Chalmers: Phys. Rev., 82(1951),106. U.M.Martius and K.V.Gow: Canad. J.Phys., 33(1955) ,225.

(10) 山本，行口および青楖：Phys, Rev, 102(1956) 1295；応届物理, 26(1957)，639；Sci. Rep. RITU., A 10(1958), 20 .

(11) R.M.Bozorth and J.G.Walker: Phys. Rev., $79(1950), 888$.

(12) W.C.Elmore: Phys. Rev., 53 (1938),757. C.D. Mee: Proc. Phys. Soc., A 63 (1950), 922. W. Andrä: Ann. Physik, 15(1954), 135; 17 (1956), 233. E.O.Hall: Proc. Phys. Soc., B70(1957), 254.

(13) L.F. Bates and E.D.Issac: Proc. Phys. Soc., $73(1959), 14$. 


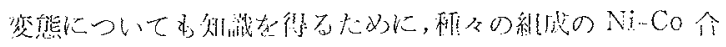

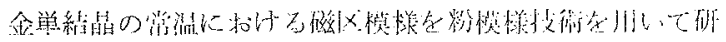

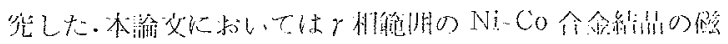

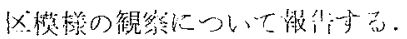

\section{II. 結晶試料と実験の手繶き}

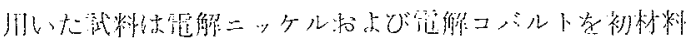

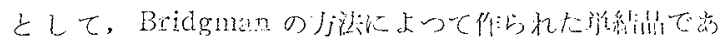

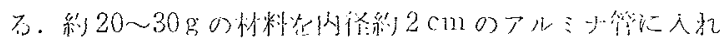

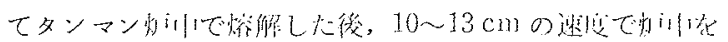

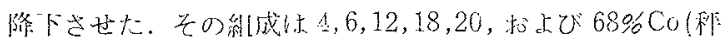

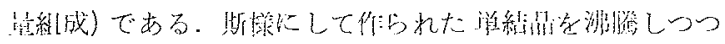

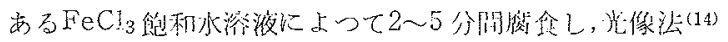

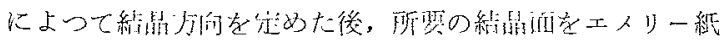

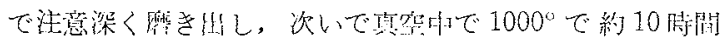

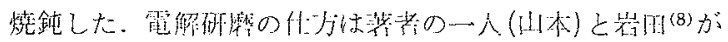

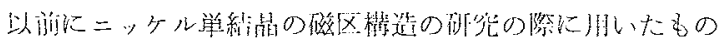

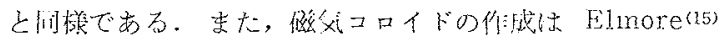

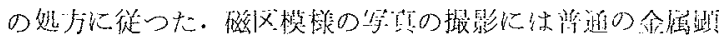

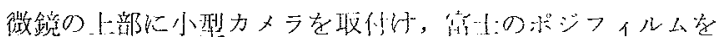

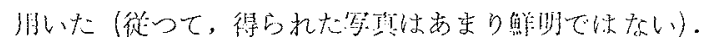

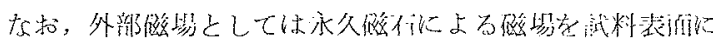

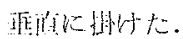

\section{III. 実験䋨果}

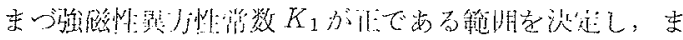

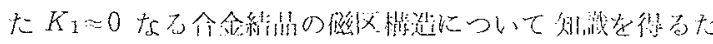

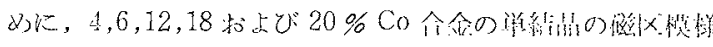

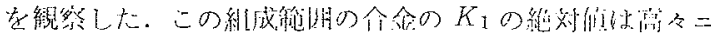

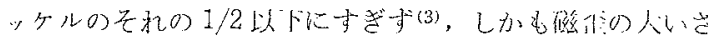

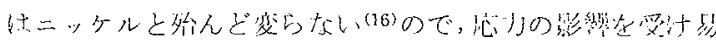

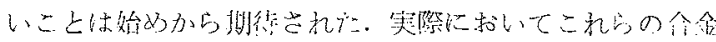

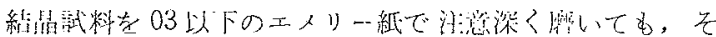

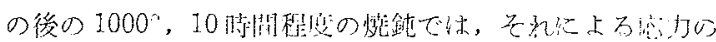

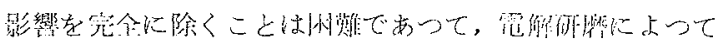

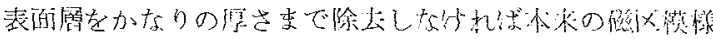

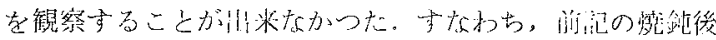

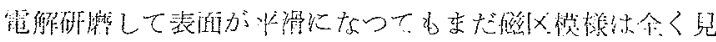

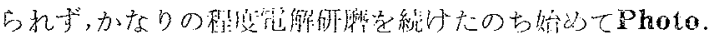

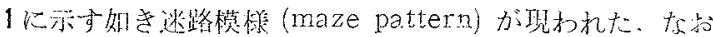

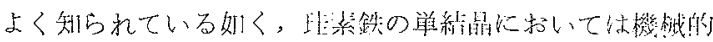

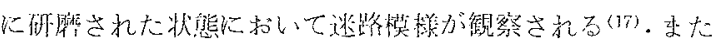

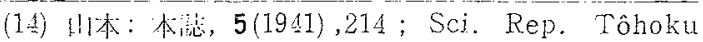

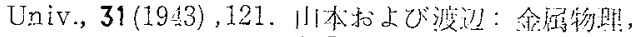

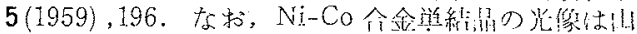

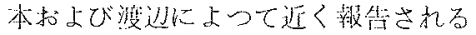

(15) W.C.Elmore: Phys. Rev, 54(1938), 1092; 62 (1942), 186 .

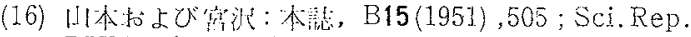
RITU, A5 (1953), 113.

(17) H.J.Williams, R.M.Bozorth, W. Schockley: Phys. Rev., 75(1949), 155.

(18) J.W.Shin and Tsu-Yen Chai: Phys.Rev, 55 (1939), 1265 .

Shih to

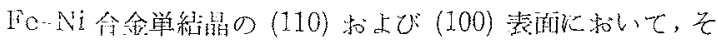

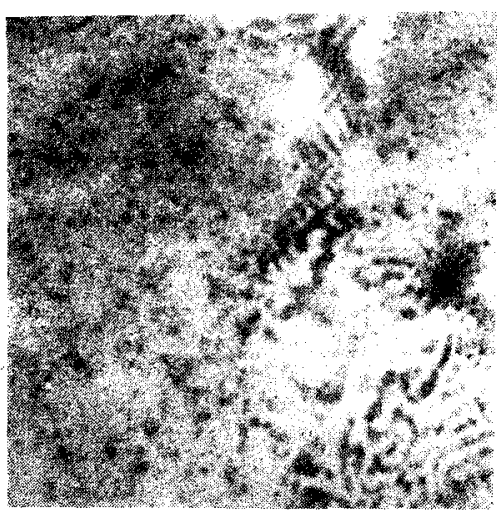

Photo.1 Maze pattern on a fairly severely electropolished (110) surface of $4 \% \mathrm{Co}-\mathrm{Ni}$ single crystal.

$\times 800$

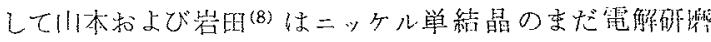
されない(110) 表佰において迷路模様を観祭した。

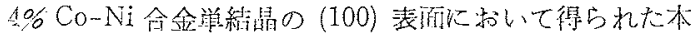

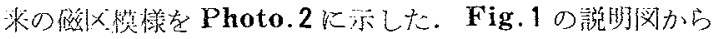

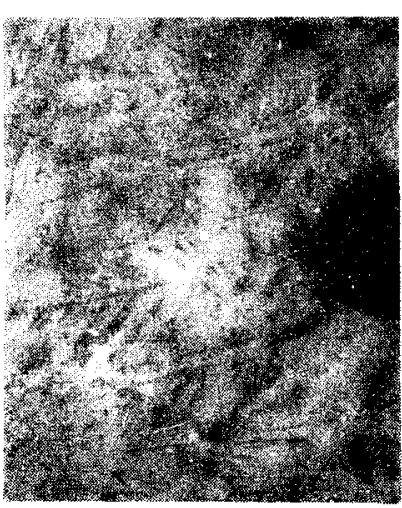

(3)

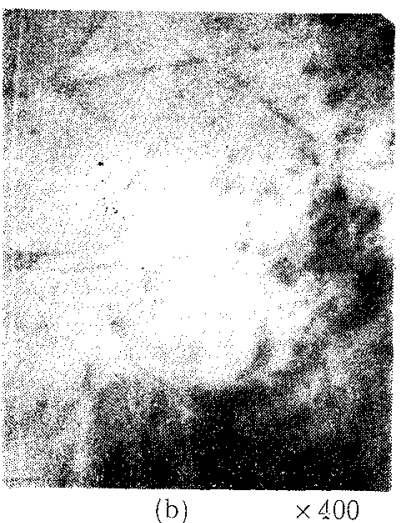

Photo. 2 Ferromagnet.jc domain patterns on $(100)$ surfaces of $4 \%$ Co- $\mathrm{Ni}$ single crystals. Vertical field: clownwards.

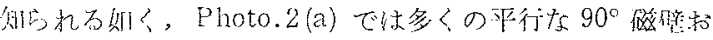

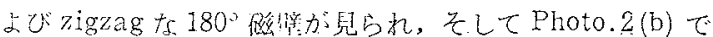
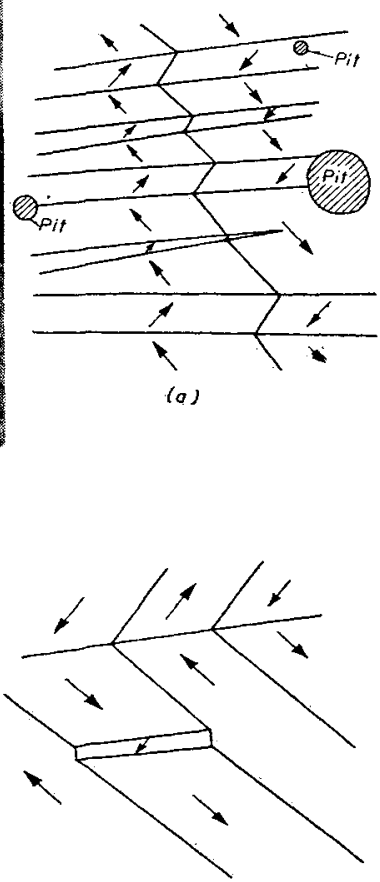

(b)

Fig. I Interpretation of Photos. $2(a)$ and $(b)$. 


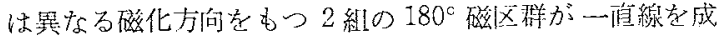

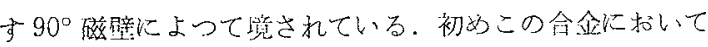
は $K_{1}<0$ であると期融された

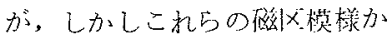
ら刘战る如く，䇲際には $K_{1}$ >0である。

Photo. 3 江 $6 \%$ Co-Ni 全金

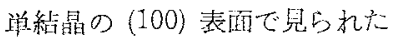
磁区模杼である. Fig.2 の院明 国加知方机当如人, Photo.3 (a) は $180^{\circ}$ 磁壁々第 1 糟 の澍 枝模漈 (tree pattern)(17) ,

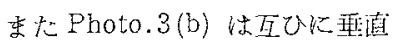
な酸化方们をるつ2組の $180^{\circ}$ 磁区群が交叉した所比生した衫 嶕な $90^{\circ}$ 磁区辢を晲わし，従つ てこの命金炕扰いては主 $K_{1}>0$ で あることを祘している。

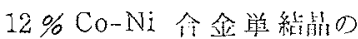

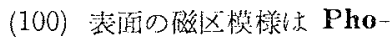

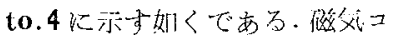

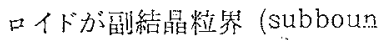
daries）集中しているために 写真は冢まり明睹でないが，

Fig.3の説明闵化示した如く，

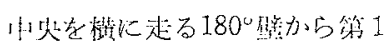
種の樹枝模椂が出ているのが見 られる・従ってこの合金に扔 いてむ $K_{1}>0$ でする。

t大颃，Photo. 5 は $12 \% \mathrm{Co}-\mathrm{Ni}$

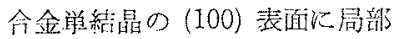

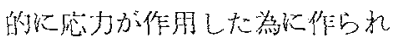

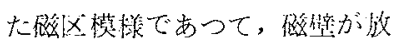
射状比て招り，そして磁化一 クトルもほ汪放射状见是つてい ることが striation から知机 る。こ机から,この全食の磁化

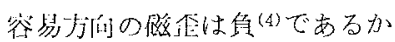

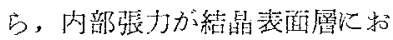
いて荷重点致中心として同心月 的比分附していることが知ら机 る。こ机快近何らの $24 \% \mathrm{Fe}$ -

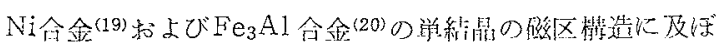

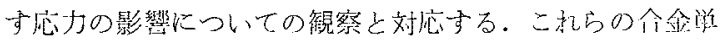

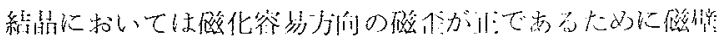

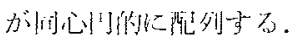

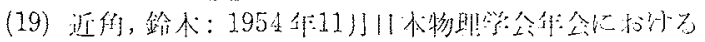

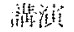

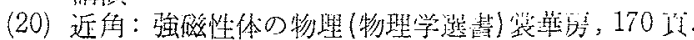

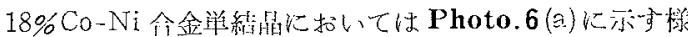
なイ䙺则な磁区模锹が主として観然されたが，これは $K_{2}$
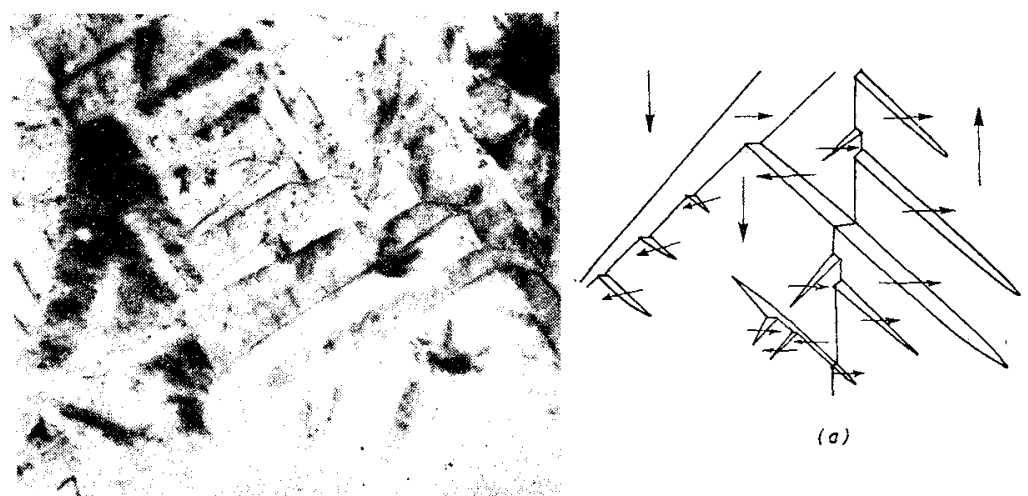

(o)

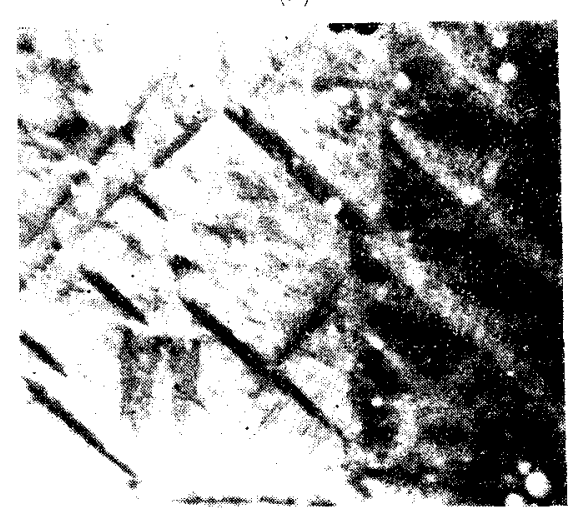

(b)

Photo. 3 Ferromagnetic domain patterns o! (100) surfaces of $6 \%$ Co-Ni single crystais. (a) Vertical field: downwards; (b) upwards, $\times 120$

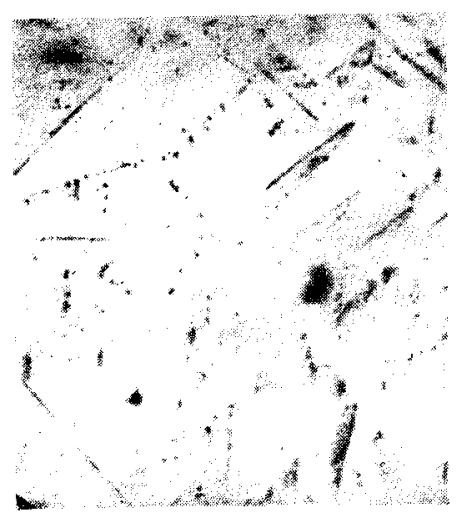

Photo. A Ferromagnetic domain pattern on the (100) surface of $12 \%$ Co-Ni single crysta1. Vertical field: downwards. $\quad \times 400$.

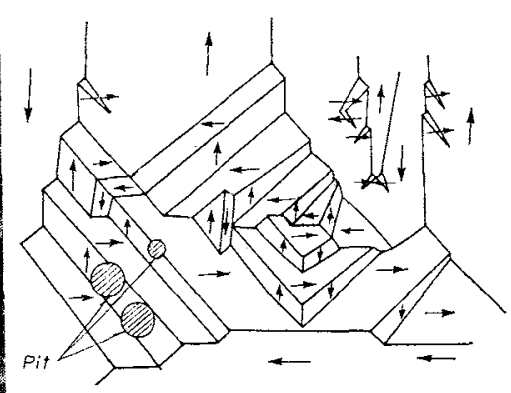

(b)

Fig.2 Interpretation of Photos. 3 (a) and (b) .

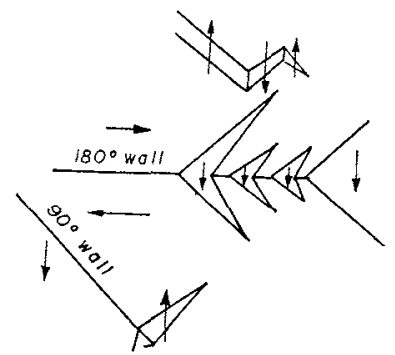

Fig. 3 Interpretation of l'hoto.4.

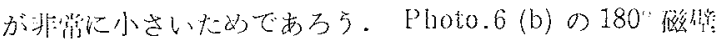

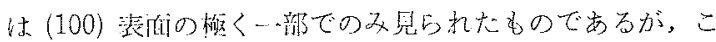

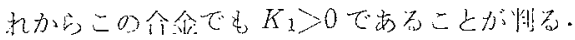

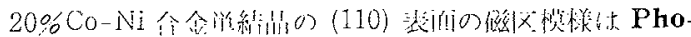
to.7 以

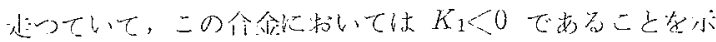
している. 


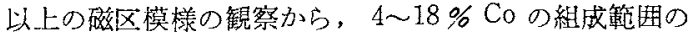
Ni-Co 合金に扣いては $K_{1}>0$ であり，をして $20 \%$ Cok

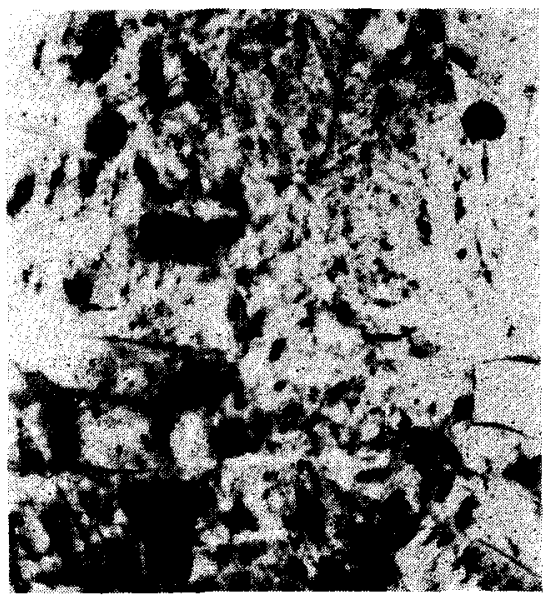

Photo. 5 Radial domain pattern on the locally strained (100) surface of $12 \% \quad \mathrm{Co}-\mathrm{Ni}$ single crystal. Vertical field: upwards. $\times 130$
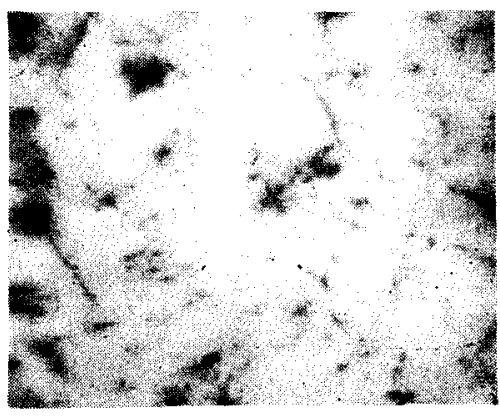

Photo.7 Ferromagnetic domain pattern on the (110) surface of $20 \%$ Co-Ni single crystal. Vertical field: downwards. $\quad \times 400$

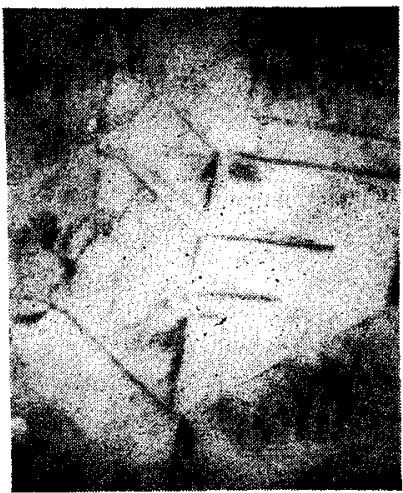

Photo. 8 Ferromagnetic domain pattern on the (110) surfaceof $68 \%$ Co-Ni single crystal. Vertical field: upwards. $\quad \times 400$

括いては $K_{1}>0$ であることが明らかである。

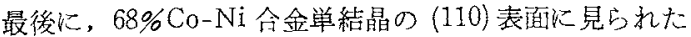

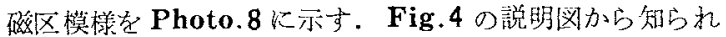
る如く，Photo. 8 には， $180^{\circ}, 109^{\circ}$ および $71^{\circ}$ 磁壁が存在
し，また中央の上下に走つている $109^{\circ}$ 酳壁には第3 種の 樹枝模椂 ${ }^{(8)}$ が見られる。従つて，この合金恃面心立方型で

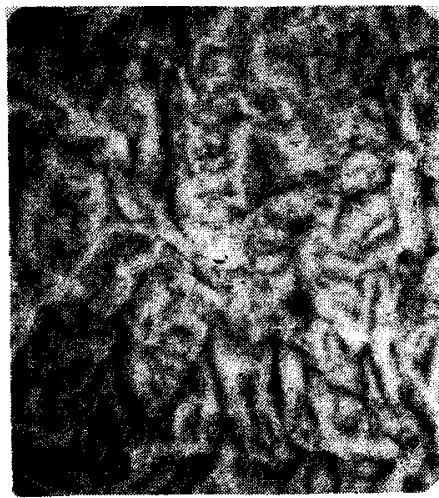

(a) $\times 110$

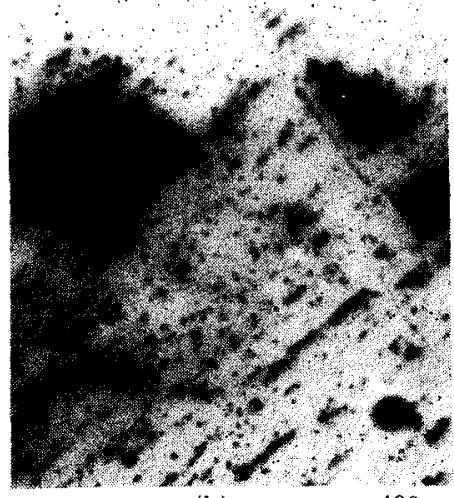

(b)

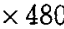

Photo 6 Ferromagnetic domain patterns on the (100) surface of $18 \%$ $\mathrm{Co}-\mathrm{Ni}$ single crystal. Vertical field: lxpwards.

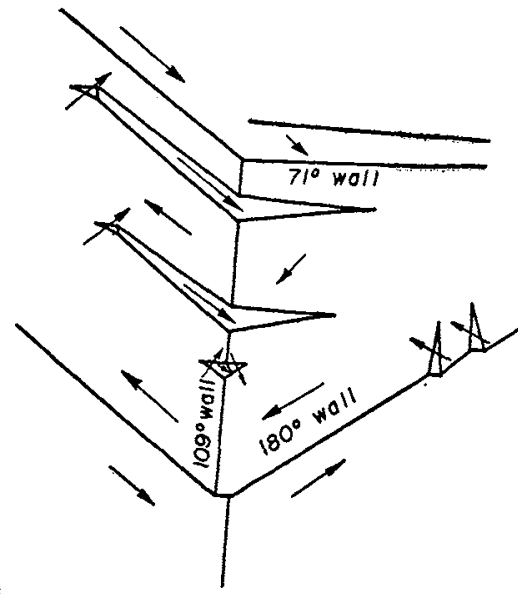

Fig.4 Interpretation of Photo. 8.

あつてから $K_{1}<0$ である。

IV. 総括

面心立方型 $\mathrm{Ni}-\mathrm{Co}$ 合金比ついて第 1 強磁性異方性常数 K 1 が正である組成範围をたしかめ，また $K_{1} \sim 0$ なる金属 
結晶の磁区構造てついて知識を得るために, 電解ニッケル 扣よび電解コバルトを初材料として Bridgman の方法に よつて作つた $4,6,12,18,20$ および $68 \%$ Co の組成の合金 単結晶の磁区模檺を粉模椂技術を用いて研究した。

まず４２0％ Co 合金の単結晶については， $K_{1}$ が小さ

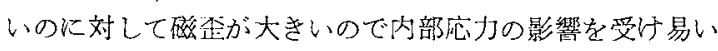
ために，1000，10特閒の焼鈍後電解研磨をかなり強度に 行つても，本来の磁区模㥞は観察されずに迷路模樣がよう

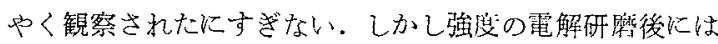

本来の磁区模様が観察され，そしてそれらの磁区慔嵄を解 析した結果 4〜 $18 \%$ Coでは $K_{1}>0$ であり，そして $20 \% \mathrm{Co}$

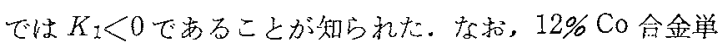
結晶の（100）表面においては鼠部的な応力を加光た場合

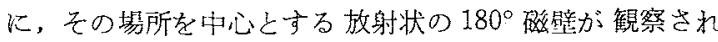
たが，この合金の容易酳化方的の磁珰は負であるからこ の磁区模样は内部張力が結晶表面以执いて荷重点を中心と して同心円的に分布していることを宗す．最徯に，68\% Co 全金単結晶は面心立方型でから $K_{1}<0$ に対応する磁区模 様を現わした。 